\section{Going viral in Parkinson's disease}

\author{
By Kai-Jye Lou, Staff Writer
}

University of Cambridge researchers have fused a virus-derived peptide that crosses the blood brain barrier with a neuroprotective RNA to generate a conjugate that can be delivered noninvasively to the brain in Parkinson's disease models. ${ }^{1}$ The group is now elucidating the details of the neuroprotective mechanism and determining the smallest RNA domain needed to elicit the effect.

Multiple groups have previously used viral vectors to deliver therapeutic genes directly into the brain in preclinical models of $\mathrm{PD}$, but John Sinclair, a professor of molecular virology at the University of Cambridge, thinks the safety and efficacy issues make it unlikely that such methods will easily translate into the clinic.

"We did not think intracranial injection with viral vectors that encode the RNA would be a viable option because this type of delivery often leads to a long-term loss of expression and the procedure itself is very invasive," he said.

In 2007, Sinclair's group showed that a $2.7 \mathrm{~kb}$ noncoding RNA transcript derived from human cytomegalovirus (CMV) interacts with mitochondrial complex 1 (MC-1) and protects neurons from premature death. $^{2}$

Deficiencies in MC-1 activity are linked to PD, and Sinclair's group hypothesized that the CMV-derived RNA transcript could help protect against this deficiency.

"If we were going to be serious about eventually using this RNA as a therapeutic, we needed to figure out how to effectively deliver it to a patient, perhaps repeatedly," Sinclair told SciBX.

A potential solution came from a Harvard Medical School team that published in the same year a method to deliver small interfering RNA cargoes across the blood brain barrier using a modified peptide derived from the rabies virus glycoprotein (RVG) ${ }^{3}$

Sinclair and his team have now fused the neuroprotective domain of their CMV-derived RNA transcript, called p137 noncoding viral RNA, to the modified RVG peptide.

In adult rats, tail vein injection of the conjugate three days prior to or three days after neurotoxin-induced injury of dopaminergic neurons improved postinjury motor performance compared with injection of the same RVG peptide conjugated to a control RNA transcript. The conjugate also prevented neurotoxin-induced loss of MC-1 activity in the mitochondria of dopaminergic neurons, whereas the control conjugate did not.

Results were published in The Journal of Experimental Medicine.

"Mitochondrial stress and free radical-induced toxicity are known to contribute to many neurodegenerative diseases," noted Matthew Wood, professor of neuroscience in the Department of Physiology, Anatomy and Genetics at the University of Oxford. "This noncoding viral RNA could in theory be broadly applicable to neurodegenerative diseases that have similar disease mechanisms."

Sinclair agreed. "We also plan to evaluate our conjugate's ability to protect neurons in preclinical models of Alzheimer's and Huntington's disease," he said.

Wood noted that the Cambridge study is the first example he's seen showing that the RVG peptide could be used to deliver a long strand of viral RNA to the CNS, as opposed to delivering only siRNA, which confirms the value of the peptide for delivering RNA payloads in general.

p137 is about 800 nucleotides long. In contrast, siRNA molecules are usually less than 25 nucleotides long.

\section{Time is of the essence}

Sinclair said his group is now trying to determine the minimum domain of the 137 RNA that can still protect neurons from premature death. The group also is studying the mechanism by which p137 RNA and MC-1 interactions protect the enzyme's activity.

- John Sinclair

Perhaps most importantly, Sinclair said the team will need to determine how late the conjugate can be delivered during the course of neurodegeneration before its neuroprotective effects are lost.

"What would clearly be a crucial complement to the development of our conjugate in Parkinson's is developing methods to diagnose the disease earlier," he told SciBX. "Because our molecule is protective and prevents further degeneration, earlier diagnosis would help maximize the number of neurons that are still functioning when treatment begins."

Indeed, Wood noted that in $\mathrm{PD}$, the majority of dopaminergic neurons have already degenerated by the time symptoms manifest.

He also said it will be important to determine the conjugate's duration of effect and to explore modifications that increase the stability of the RNA payload.

The University of Cambridge has filed for a patent covering the use of the viral nucleic acids to treat neurodegenerative diseases. The work is available for licensing from Cambridge Enterprise Ltd., the university's technology transfer arm.

Lou, K.-J. SciBX 5(6); doi:10.1038/scibx.2012.141

Published online Feb. 9, 2012

\section{REFERENCES}

1. Kuan, W.-L. et al. J. Exp. Med.; published online Dec. 19, 2011; doi:10.1084/jem.20111126

Contact: John H. Sinclair, University of Cambridge, Cambridge, U.K. 


\section{ANALYSIS}

e-mail: js@mole.bio.cam.ac.uk

Contact: Roger A. Barker, same affiliation as above e-mail: rab46@cam.ac.uk

2. Reeves, M.B. et al. Science 316, 1345-1348 (2007)

3. Kumar, P. et al. Nature 448, 39-43 (2007)

\section{TARGETS \& MECHANISMS}

COMPANIES AND INSTITUTIONS MENTIONED Cambridge Enterprise Ltd., Cambridge, U.K. Harvard Medical School, Boston, Mass.

University of Cambridge, Cambridge, U.K. University of Oxford, Oxford, U.K. 